Undergraduate Use of CD-ROM Databases:

Observations of Human-Computer Interaction and Relevance Judgments

Debora Shaw

School of Library and Information Science

Indiana University

Acknowledgement: The author thanks Edit Kontra for transcribing the search observations.

Direct correspondence to Debora Shaw, School of Library and Information Science, Indiana University Library, Room 012, 1 Indiana University, Bloomington, Indiana 47405 <shawd@indiana.edu>

\begin{abstract}
Ten students in a freshman Elementary Composition course were observed as they searched bibliographic databases on a CD-ROM LAN. All were preparing term papers, and were asked to think aloud as they conducted their searches. A total of 329 relevance judgments were made as the students searched an average of 2.7 databases per session. Basic familiarity with computers and a tendency to get out of unproductive searches helped in avoiding problems with the variety of databases and search interfaces. All students found records they chose to print, with relevance judgments often made from information in the controlled vocabulary, title, or abstract. The browse interface was used most often, and its similarity to InfoTrac was helpful. Some students were able to use keyword access effectively, though Wilsondisc's multiterm search required adjustments and adaptation of strategies. SilverPlatter's record display and print functions caused confusion for searchers unfamiliar with this interface.
\end{abstract}

Bibliographic databases on CD-ROM are as common a tool as the photocopier or word processor in writing term papers for today's undergraduate students. While the various search interfaces are touted as easy to use, many librarians find students do not use them intuitively and must have their CD-ROM searching skills developed through bibliographic instruction. Relatively little has been documented about how students actually use these databases, which interface features they select, or where they encounter problems. Better understanding of the successes and failures in CD-ROM searches may suggest ways of improving bibliographic databases, search interfaces, and bibliographic instruction. This information can also be helpful as collection development decisions are made regarding preferred media (CD-ROM, local online files, or vendor services) and search engines for bibliographic databases.

\title{
Review of Related Research
}

In the mid-1980s the introduction of InfoTrac, soon followed by other bibliographic databases on CDROM, was greeted with enthusiasm by academic library users and staff (Beltran, 1986; Flynn, 1989; Kleiner, 1987). The ease of computer-based searches when compared with working through printed bibliographies appealed to users and the predictable (if high) cost appealed to librarians who may have discouraged online searching because of concern over unpredictable costs (Bartenbach, 1990; Erkkila, 1990).

Researchers have looked at the repercussions of CD-ROM database searching from various perspectives. One area of interest has been implications for bibliographic instruction and the need for individual assistance to library users (Leach, 1989; Reese, 1989; Whitaker, 1990). There have been various attempts to assess humancomputer interfaces for bibliographic database searching, both from a sense of the ideal interface and in the context of reviewing CD-ROM products (Shaw, 1993; Tuckett, 1988).

Another important avenue of research considers CD-ROM searching from the user's perspective. Allen (1990) studied the preliminary but potentially critical step of database selection, and DiMartino, Ferns and Swacker (1995) investigated how language skills affect search techniques. Belander and Martin (1990), Bucknall and Mangrum (1992) and Steffey and Meyer (1989) present attempts to investigate user satisfaction with CD-ROM 
searching. Several studies have used techniques from psychological research to identify individual differences or cognitive aspects of CD-ROM use by novice searchers. (Balaraman, 1991; Puttapithakporn, 1990).

Searching bibliographic databases is clearly a complex undertaking, and various methods of analysis are needed to comprehend the interaction between searcher and database. Direct observation of searchers who describe their searches is one approach which has a number of benefits (Patton, 1980). This technique can reveal problems of which the user is not aware and which a researcher does not anticipate with a survey. Such observation provides access to ideas and reactions at the time of the search, although a searcher thinking aloud and aware of an observer cannot be exactly the same as a typical, unobserved searcher.

Research on use of online catalogs is similarly complex and provides comparable challenges to the researcher. Several studies have analyzed transaction logs of OPAC interactions, observing that searchers alter strategies when a search is perceived as failing, and are often quite persistent in reading through large numbers of retrieved citations (Sullivan and Seiden, 1985, Wallace, 1993, Wiberley, Daugherty and Danowski, 1990). Other studies of online catalog searching have used detailed observation of individual searchers. For example, Hert's (1995) research identified 18 elements of the search interaction associated with the searcher, the problem or project, and the system responses which affect a searcher's actions. Puttapithakporn (1994) developed a model of the conceptual framework underlying online catalog searching and identified various types of errors made by students who thought aloud as they used an online catalog.

Detailed search observations entail intense interaction and observation, reducing the number of subjects which can reasonably be observed; however, the depth of information on each provides a rich sense of the nature of searching and the context and evolution of information needs. Because few subjects are involved, reports of the research often cannot use statistical measures of significance, but rather rely on repeated observation and statements of the subjects to identify important findings. Fister (1992) and Kuhlthau (1988) conducted detailed studies of successful undergraduate researchers, noting the considerable effort extended in selecting a topic and the iterative nature of the research process.

The study described here involves detailed analysis of CD-ROM searches, focusing on understanding the users' information needs and their use of bibliographic databases to meet these needs.

\section{Observations of CD-ROM Searches}

In the spring of 199310 students enrolled in Elementary Composition at Indiana University were observed as they used bibliographic databases over Indiana University Libraries' CD-ROM local area network (LAN). Half the students were from a basic skills (remedial) section of Elementary Composition and half were from a general section of the course. Both sections were instructed by graduate student associate instructors. The students had been introduced to CD-ROM searching in class, and all were conducting searches for their term papers. Each student received $\$ 5.00$ for taking part in the study.

The CD-ROM LAN, part of the Indiana University Libraries research collection, provided access to nine databases: Dissertation Abstracts, Educational Resources Information Center (ERIC), Humanities Index, MLA International Bibliography, Philosopher's Index, PsycLit, Religion Index, Social Sciences Index, and SocioFile. To use any of these resources one connected to the LAN menuing system, then selected the file to be searched. The LAN did not provide access to the online catalog or to the InfoTrac database, which were accessible from other workstations.

Students spent from 30 to 50 minutes searching. They were asked to think aloud throughout the search, explaining their thought processes, how decisions were made, problems they encountered, etc. When the students had trouble remembering to describe their thoughts they were prompted by the observer. The sessions were tape recorded and transcribed. In addition, the observer took notes on the interaction, particularly on the number of records retrieved in response to queries. At the end of the sessions the students were asked about their feelings about searching and their next steps with the information they had retrieved. The discussion below follows the general sequence of the search, from information need to database selection, search strategy, selection of records to print, stopping the search, and next steps on the term paper. Student comments are italicized in the following discussion. Comments on the CD-ROM interfaces, InfoTrac, and bibliographic instruction conclude this section. 


\title{
Information Needs
}

Students' term paper topics covered a wide range of issues. In some cases they came from textbook lists. Topics as expressed by the students at the start of the searches were:

\author{
Afro-American experience as reflected in collegiate athletics \\ Japanese internment during World War II (2 students) \\ Fairy tales are bad for children \\ Abortion (since everybody is doing abortion, I guess I'm going to do abortion too) \\ Equal pay for men and women in the workforce - need to find a solution for the problem \\ Effects of Saturday morning ads on children \\ Dialects in America - the effects it has, maybe through education \\ How housing affects animals in pet shops \\ Sleep phases or the meaning of dreams
}

Six students were at an initial search stage, while one had notes on possible sources after a preliminary discussion with the associate instructor and three had done InfoTrac searches but needed more material.

Simply having selected a topic was not always enough to begin searching. Before using the workstation at all one of the students working on Japanese internment had a preliminary information need: to find out the meaning of "internment." He consulted the textbook for his class, looking first at the table of contents, and found, "It has something to do with the war." This student had an additional problem in entering search terms, as he consistently used the misspelling "Japanese interment" even after seeing the word spelled correctly in the textbook.

\section{Evolution of Search Topics}

Some students maintained a focus throughout the search. The student working on equal pay for equal work had done some database searching before this observation, and at this point needed to "find a solution." During the observation she kept returning to this focus, rejecting citations which she felt would not provide "a solution." This was the most focused of the searches observed, but others also encountered possible diverging paths which were not followed. Another searcher found very little on her topic, but was not yet ready to abandon it, "I'll either have to look somewhere else or I'll have to pick a different topic."

In a few cases the observations did show evolution of search topics. The student exploring Saturday morning TV ads considered children's television programs, cartoons, governmental regulation, children and smoking, and connections between television and toys as she reviewed citations. She concluded, "I have choices now."

In many cases the initial information need was directed or focused through the search; availability of records or interests of the searcher helped the initial statement evolve into an embryonic term paper. Students who had done some previous searching and were looking for pieces to fit into an already-formed structure had more trouble finding the right citations than did students in the initial, exploratory search mode.

\section{Database Selection; Changing Files}

Although the students had used the online catalog and InfoTrac, and had been introduced to database searching in class, the ability to search several different files from a single workstation was new to many. They did use many databases, however, with an average of 2.7 files per search. The most adventurous was the student looking for material on Afro-Americans and collegiate athletics, who eventually searched in six different files: Social Sciences Index, Humanities Index, ERIC, SocioFile, Dissertation Abstracts, and PsycLit.

Selecting a database from the LAN menu was not an easy decision for the students to describe. Sometimes the name of a database revealed enough about its content to assist the searcher, for example with Social Sciences Index or Humanities Index. More subject-specific database names were intimidating for some users, for example 
"why do they call it 'PsycLit'? When I saw that I was like, 'Oh, that's for psychology majors.' It just seemed like it was really, really academic and for graduate students." In other cases searchers recalled having used a database before and selected it based on this experience. The LAN menuing system helped with database selection by providing a short description at the bottom of the screen as each database was highlighted.

Many students changed databases during the search. The choice of a second database was even less well understood, since what had seemed to be the most appropriate database had already been tried and found inadequate. The Wilsondisc interface presented a potential problem, since it included an option to search journal titles as a separate file. This was confusing for the two students who stumbled into this option, since there was no obvious difference between the journal subscription file and the various bibliographic databases accessible on the LAN. Almost miraculously both students did escape from the journal subscription file without much trouble and without wasting much time.

\section{Search Strategy}

Search strategy is influenced by the searcher's ability, experience, and expectations for the search, but also by the capabilities of the search software used. Many of the available databases were Wilson products, with both browsing and "multiterm search" options listed when the database was accessed. All students used at least one Wilson database; four used the browse mode only, one used multiterm search only, and five used both interaction methods.

Success in subject browsing depends in part on selecting the right database. For example, the searcher working on animals in pet stores searched the Humanities Index, where "leash laws" found the nearest entry as "leather" and a subsequent search on "canine" retrieved "cannabis," leading to the observation, "I don't think this university is interested in dogs at all." In a search for "humane society" the student specifically relied on the system to correct her spelling: "How do you spell 'society,' suppose? s-c-i-e-t-y - probably not right. We'll fake it out. Well, they spelled it for me anyway, and they put an 'o' in there!" The browse mode also showed see references from unused terms, but the student was unable to discover how to move from the cross reference "animal behavior (psychology)" to the preferred term "animal behavior" so she then moved to the multiterm searching. Another student moved from browsing for "equal pay for equal work" to the multiterm search. She found the same number of records with both search modes and assumed (correctly) that the search with two subjects (equal pay AND equal work) retrieved the same records.

Three students employed sophisticated strategies where multiterm searching complemented browsing keyword searching to locate appropriate terms from the controlled vocabulary which were then entered in the browse mode. For example, one used the multiterm search for "Japanese AND American AND relations," then paged through the entries to find "for this article the subject covered says 'race relations, United States history, and Japanese-Americans - evacuation and relocation.' This article is what I was looking for. I looked at this covered subjects and it says 'race relations' and that's race discrimination between Japanese and Americans, so I am going to look for these keywords."

The student working on children and advertising saw searching as a challenge or puzzle. When "television advertising" AND "social effects" retrieved nothing, she said, "pretty specific — I'll work around it," and substituted "social aspects" for the second term, producing nine records. She observed, "it's pretty picky" and changed "children's programming AND advertising" (2 records) to "children's programs AND advertising" for five records.

Some students also used the numbers of records retrieved with each term in devising search strategies. To increase the number of records retrieved one searcher changed "collegiate" to "college" and "athletics" to "athletes." To decrease the number of records students added concepts; for example "social AND Japanese" was changed to "social conflict AND Japanese AND American." In another search "Standard English AND dialects" retrieved 114 entries, so the search was revised to include "American." 
Puzzling over the retrieval system, a searcher observed, "How come I did 'children's advertising' and had zero, then changed to 'children AND advertising' [and found five]? So they just don't like nouns as adjectives, I guess." Another described the multiterm search as "playing with words, you have to come up with the idea and put the keywords." He recommended browsing for searchers who do not have "really narrowed down ideas."

There was a sense of an optimum number of records to be reviewed. When asked, two searchers mentioned 20 as about right. Retrieval sets that were judged too large ranged from 39 to 185 records.

The students who used keyword searches showed considerable sophistication in working with retrieval results to modify queries and adjust the number of items retrieved. Some also understood use of controlled vocabulary to increase recall or the use of additional search terms to increase precision. As described above, they also speculated on why spelling differences or different synonyms produced different results.

\section{Selecting Records}

During the observations a total of 329 relevance judgments were recorded, with 145 records printed and 184 rejected. The students often had trouble expressing why they chose or rejected certain records. Sometimes their explanations were simply reading a few words from the record or "I don't want that," or "I'm not interested." Often a record was examined and was simply not on the topic — "not interesting," or "not intriguing." Sometimes "not intriguing" appeared to mean "does not agree with my opinion." For those who used SilverPlatter the display of search terms in a different color was helpful in focusing the relevance assessment.

Various parts of the bibliographic citations were used in determining whether a record should be printed; the frequency of use of various fields is given in Table 1. The most frequent source of information was a general impression of what the record was about. Not surprisingly, the title of an article was often quoted as an indicator of content. Subjects as reflected in the controlled vocabulary were also helpful in assessing relevance, as well as in developing search strategy as noted above.

Table 1.

Considerations in Relevance Assessments*

Keep (145 records) $\quad$ Reject (184 records)

Title

Subject

(controlled vocabulary)

Abstract

Author 
Source/journal

Language

Date

* Note: some relevance judgments were based on more than one factor.

The abstract proved especially helpful for many students, even if they did not know the name of the field. Students described the abstract as "a brief summary of what the article is about," "the stuff," and "the little extra." One student had a clear idea of how his paper on abortion would approach the topic, and was able to predict (he believed) what an article would be about. He explicitly considered how each articles would fit into his paper, identifying those which could be used in the introduction or conclusion, as evidence to back up his arguments, to contradict his thesis, as the conclusion to a paragraph, or to provide statistics to make his paper more than just an opinion piece.

Length of the article was also considered on occasion, with shorter articles more likely to be printed. Apparently article length was a consideration only for marginal items, with short articles selected if other factors had not already determined that the record should be printed or skipped. The type of article was sometimes helpful in assessment, with surveys and specific reports more desirable than reviews or general studies. The author of an article was mentioned only once as a decision factor; in a search on Japanese internment, "This is a Japanese authormight be intriguing."

Occasionally the journal title was used in assessing a record. Some students specifically sought articles from a variety of journals and magazines to provide diversity of opinion. There was also a tendency to judge a journal by its title, sometimes with rather strict expectations of what a journal might include. For example, the searcher dealing with dreams discovered a citation from Dance Magazine and was unsure why such a topic would be covered in this source. Potential access to the journals was mentioned occasionally as a concern. Sometimes the students made unwarranted assumptions about the Libraries' holdings, apparently believing that more scholarly titles were unavailable based on what they had seen in the Undergraduate Collections. One searcher specifically mentioned the need to check "the big red book," the Libraries' list of journal holdings.

Language of the article was a factor in some decisions, usually when the searcher could not read the language of the title. However, one searcher located articles in French, which she had studied. She remarked, "I know what it says - that's kind of neat."

The students were good at recognizing citations they had seen before, either from previous searches on InfoTrac or items that had been reviewed in earlier queries in this session. This was especially useful, as many searches used the same terms in various combinations so the same items were retrieved and reviewed several times.

\section{Stopping}

Having "enough" records printed was one factor in deciding to stop searching. For one student, having "about 13" citations would help with the next steps in the research. Another felt that five or six citations was enough, pointing out that she was required to have five for the assignment. Another student judged appropriate effort by time, "I usually spend about two hours just getting all my information to define the problem." All the students planned to consult the articles for their citations printed as the next step. For some there was a period of analysis and reflection before deciding which citations to pursue; others planned to go directly to the journals to locate the items retrieved. 
To summarize observations of search behavior, students used a variety of databases and a variety of interfaces. They tended to "escape" (using the <escape> key) from difficult situations and try different files rather than try to figure out how to overcome problems encountered. Both browsing (familiar from InfoTrac) and keyword searching (familiar from the library's online catalog) were used; sometimes word selection was haphazard, other times carefully planned, as when a keyword search was used to reveal controlled vocabulary terms for a subsequent browse search. Record selection was generally based on how "interesting" an article sounded; in cases where students identified the portions of the records helping make these assessments the title, subject terms, and abstract (if present) were the primary indicators. Students generally had a sense of how many records they were willing to look through in a retrieval set (about 20), and how many items they wanted to have printed (fewer than 20) before proceeding to look for the journal articles.

\section{Observations on CD-ROM Interfaces}

The students had a general sense of how to interact with computers, a reservoir of knowledge which was often helpful in negotiating the CD-ROM LAN as well as in interacting with the specific search software. This general knowledge reflects the emergence of conventions or de facto standards for both hardware and software. For example, <escape> to back out of something, <enter > to select, and <F1> for help seemed second nature. One student, when asked how she knew to press <escape> remarked, "well, you're absolutely right, it didn't tell me to do that whenever I try to get out of something." Having on-screen directions was helpful, especially as keyboard templates tend to disappear and would not be useful in the networked setting with each workstation used to search various CD-ROM systems.

The majority of interactions observed were with the Wilsondisc interface. Problems with the journal subscription file have been discussed above. The browse search was not intuitively obvious, but students seemed to catch on easily to the idea of typing in a word and seeing a list of subjects, then <enter> to see a bibliographic record. The multiterm search seemed to make sense to most searchers who used it.

Exiting from the Wilsondisc system was confusing for one student, who tried to use the <escape> key to back out and received an embarrassing <beep> when the system required a specific choice to exit the system. Wilsondisc automatically advanced to the next record after a record was printed and to the search screen when the last record in a retrieval set was printed. This was confusing to some students, one of whom remarked "Why didn't it just go back to where it was? stupid ... waste of time."

The SilverPlatter interface presented difficulties for students accustomed to InfoTrac and Wilsondisc. After selecting ERIC or PsycLit from the LAN menu the students had to press the space bar to select subfile(s) for the CD$\mathrm{ROM}(\mathrm{s})$ to be searched. In four of the eight observations of SilverPlatter database uses, students had the natural reaction of pressing <enter> instead of the space bar, producing the disconcerting message "You cannot search a database until you have selected it," somewhat confusing since the students had just selected ERIC from the LAN menu. Commands which use the <break> key in combination with others confused two students; the use of two keys for one function is not common, and locating the <break> key required extra effort as well.

The basic blank screen and "Find:" prompt was intimidating for some; one student spent considerable time thinking in silence when confronted with the initial SilverPlatter screen. When he did enter "Blacks College Athletics" there was a relatively quick response of the number of records for each term, but the Boolean combination took so long that he pressed <enter>, then considered using the index search capability before the results appeared.

It was evident to the observer that moving through a retrieval set in SilverPlatter was not as easy as in Wilsondisc. The idea of "marking" records to be printed later was not clear to these searchers, two of whom used the Wilsondisc command F4 to print, then tried to figure out why nothing happened. One of the two searchers who eventually figured out the marking and printing said, "I could just write it down. That would be much easier." Another SilverPlatter user simply relied on the <print screen> key to print what she needed. 


\section{InfoTrac}

InfoTrac was clearly the most familiar, almost "standard" search system for these students; some referred to the LAN CD-ROM databases as "InfoTrac" — a generic term for bibliographic databases, which they distinguished from the library's online catalog. Others differentiated between InfoTrac and the LAN-accessible databases. One student used printouts from his InfoTrac search to provide keywords for a search in the Social Sciences Index. Several mentioned InfoTrac as one of the next steps in gathering information for their papers.

\section{Library Instruction}

Bibliographic instruction was mentioned occasionally, even though not a specific topic of this investigation. Students had been introduced to database searching in their composition classes, and some had experience searching InfoTrac before coming to college.

Students commented on librarians as well. The student who misspelled "internment" said, "Right now I'd ... maybe ask for help from one of the librarians to see if she can help me look up something." Some students were reluctant to ask for help, for example mentioning the value of the on-screen instructions because the searcher does not need to bother a librarian, "taking time while they could be helping someone else." One student had used a Wilson database at another library with an online search option. A notice cautioned against unnecessary use because of the costs. She observed, "I'm afraid they're watching me - that scares me... So I said, 'OK, this is going to cost me, I'm going to mess up and they're going to fine me, 'that just scared me."

\section{Discussion}

These undergraduate searchers showed considerable skill in interacting with different search engines. There were no obvious differences between students from the remedial section and those in general Elementary Composition. Only three students relied on just one interface throughout the observation. The often second nature or automatic ability to understand the different interfaces or to get out of unpromising situations may be especially useful in coping with the range of computer-based information systems to which these students have been and will be exposed. Sullivan and Seiden (1985) found that searchers in an online catalog attempted to recover from problems at an intermediate level, rather than starting over at the beginning. This study observed such behavior, for example the "playing with words" approach to searching, but also a willingness to jump to a different database and start with a "clean slate" if a search was not going as desired.

LAN access to several CD-ROM systems introduced the problem of finding "the right" database, or even a "good enough" database, which was handled in various ways. Most students tried more than one database on the LAN, and said they would rely on InfoTrac if these searches were not sufficient. The journal subscription database "trap" on the Wilsondisc databases snared two students, but they were able to extricate themselves reasonably expeditiously; a striking contrast with the observation of graduate student searchers (Shaw 1995). The search on housing animals in pet shops was perhaps the least appropriate topic for the databases available, a concern the student had discussed with her instructor; she eventually decided to choose another topic for her term paper.

InfoTrac was clearly the point of reference for most of these students, and the browse mode searching on Wilsondisc therefore seemed familiar. Many students did use other search methods, and Wilson's multiterm search worked well for the relatively straightforward Boolean searches. Peters (1993, p. 51) summarized research on online catalog transactions, noting that approximately $60 \%$ of searches used Boolean operators; in this study 7 of the 10 students used Boolean searching at some point in their work. There were some problems with spelling, and the SilverPlatter blank work screen was disconcerting for students accustomed to the browsing interfaces. Some students were quite adept at keyword searching and able to use it to start citation pearl growing (Harter, 1986, pp. 183-184) - the identification of appropriate terms from the controlled vocabulary to increase the number of items retrieved. The concepts of narrowing and broadening a search proved useful to some students, while others seemed 
to have a less sophisticated tactic of guessing the lucky word - a sort of "pin the tail on the donkey" strategy. While they looked at many records during the searches, there was a general sense among the students that more than 20 in any one set was too many records to look through. The result was several searches that brought up some of the same records; these were identified easily when seen for the second and subsequent times.

All students found records they deemed worthy of printing for future use. Many were unable to explain why particular records were judged relevant, except that they were "on topic," the primary criterion identified in other observations of bibliographic information seeking (Fister, 1992, Shaw, 1995). One student in particular was carefully considering what each article would include; he anticipated where he might use each reference in constructing his term paper. This searcher had clearly internalized the "rhetorical aspect of research writing" (Fister, 1992, p. 167) which characterizes the work of successful students. The titles, subject headings, and abstracts (in the databases which had abstracts) were especially helpful in assessing relevance; students very occasionally mentioned author, language, length, article type, or journal in judging records. This is a sharp contrast with assessments by humanities graduate students, where these non-topical indicators were used in over $20 \%$ of decisions to accept or reject citations (Shaw, 1995, p. 335).

Some of the search topics changed focus as the searches progressed, but this occurred only among students who were at the preliminary exploration stage. Students who had already done some searching on InfoTrac were likely to stay with their topics, to maintain a focus and discount articles that might lead in new directions. Many students had a sense of the right number of citations needed, usually fewer than 20, to conclude their searches. Wiberley and Daugherty (1988) concluded that end users of online search systems placed retrieval ceilings at 50 items, online catalog searches at 35, and printed indexes at 10. These novice searchers clearly fall at the low end of Wiberley and Daugherty's scale. On the other hand, St. Clair and Magrill (1990) reported an average of 7.5 references per term paper for undergraduates, with freshmen averaging 6.3 references. Even if only half the 20 citations make their way into the term paper, these students' efforts would appear to be more thoroughly researched than those analyzed in the earlier study.

\section{Conclusion}

These observations of undergraduate searchers provide another perspective on the human-computer interaction in CD-ROM database searching. Searching is viewed as part of a complex interaction between information needs and resources. This complexity is not always evident in studies of online catalogs, especially when they are treated as stand-alone resources and searchers are given assigned questions rather than working from their own information needs. This study reaffirms work by Dervin (1994) and Kuhlthau (1993), among others, on the importance of holistic approaches to examining information seeking.

These undergraduate students are not without preparation for the complex world of library research. Bibliographic instruction and individual assistance from their instructors and library staff have proved important. Today's students are also often aided by their familiarity with computers and their general inclination to escape from unproductive searches. In a sense, many of them have spent their lives coping with the information explosion and what Wurman (1989) calls "information anxiety."

Interfaces for bibliographic database searching are proliferating even as librarians call for standards or at least similarity among the tools (for example the CD-ROM Consistent Interface Guidelines, 1991). Observations of the many minor and occasional major problems for student searchers demonstrate once more the consequences of the current free-for-all in interface development. While competition may eventually lead to "the survival of the fittest" interface we must continue to assess and evaluate the offerings and their suitability for various information seekers. Until the ultimate intuitive or "user intimate" interface emerges (Matthews and Williams, 1984), new searchers will need introductions to searching with sufficient emphasis on conceptual problem solving to adapt to the variety of interfaces they will encounter. 


\section{References}

Allen, Gillian. (1990). Database selection by patrons using CD-ROM. College \& Research Libraries, 51, 69-74.

Balaraman, Kamala. (1991). End-user studies in CD-ROM environment: Work in progress. Proceedings of the ASIS Annual Meeting (pp. 283-294). Medford, NJ: Learned Information for the American Society for Information Science.

Bartenbach, Bill. (1987). CD-ROM and libraries: Opportunities, concerns, challenges. Proceedings of the National Online Meeting (pp. 9-19). Medford, NJ: Learned Information.

Belander, Anne Marie \& Hoffman, Sandra. (1990). Factors related to frequency of use of CD-ROM: A study of ERIC in an academic library. College \& Research Libraries, 51, 153-62.

Beltran, Ann Bristow. (1986). Use of InfoTrac in a university library. Database, 9, 63-66.

Bucknall, Tim \& Mangrum, Rikki. (1992). U-Search: A user study of the CD-ROM service at the University of North Carolina at Chapel Hill. $R Q, 31,542-553$.

CD-ROM Consistent Interface Guidelines. (1991). Special Interest Group on CD-ROM Applications and Technology (SIGCAT), CD-ROM Consistent Interface Committee.

Dervin, Brenda. (1994). Information and democracy: An examination of underlying assumptions. Journal of the American Society for Information Science, 45, 369-385.

DiMartino, Diane, Ferns, William J. \& Swacker, Sharon. (1995). CD-ROM search techniques of novice end-users: Is the English-as-a-second-language student at a disadvantage? College \& Research Libraries, 56, 49-59.

Erkkila, John E. (1990). CD-ROM vs. online: Implications for management from the cost side. Canadian Library Journal, 47, 421-428.

Fister, Barbara. (1992). The research process of undergraduate students. Journal of Academic Librarianship, 18, 163-169.

Flynn, Ellen P. (1989). Users' reactions to InfoTrac in an undergraduate library. College \& Research Libraries News, 50, 14-16.

Harter, Stephen P. (1986). Online information retrieval, Orlando, FL: Academic Press.

Hert, Carol A. (1995). Information retrieval as situated action. Proceedings of the Annual Meeting of the American Society for Information Science (pp. 172-180). Medford, NJ: Information Today for the American Society for Information Science.

Kleiner, Jane P. (1987). InfoTrac: An evaluation of system use and potential in research libraries. $R Q, 27,252-63$.

Kuhlthau, Carol Collier. (1988). Longitudinal case studies of the information search process of users in libraries. Library \& Information Science Research, 10, 257-304.

Kuhlthau, Carol C. (1993). Seeking meaning: A process approach to library and information services, Norwood, NJ: Ablex.

Leach, Bruce A. (1994). Identifying CD-ROM use patterns as a tool for evaluating user instruction. College \& 
Research Libraries, 55, 365-371.

Matthews, Joseph R. \& Williams, Joan Frye. (1984). The user friendly index: A new tool. Online, 8, 31-34.

Patton, Michael Quinn. (1980). Qualitative evaluation methods, Beverly Hills, CA: Sage.

Peters Thomas A. (1993). The history and development of transaction log analysis. Library Hi Tech, 11 (2), $41-66$.

Puttapithakporn, Somporn. (1990). Interface design and user problems and errors: A case study of novice searchers. $R Q, 30,195-204$.

Puttapithakporn, Somporn. (1994). A qualitative analysis of user error in searching an online public catalog system. Ph.D. dissertation, Indiana University.

Reese, Jean. (1989). CD-ROM technology at Vanderbilt University: Impact on library staff and the educational community. Optical Information Systems, 9, 38-43.

Shaw, Debora. (1993). CD-ROM interfaces for information retrieval: Heuristic evaluation and observations of intended users. Proceedings of the National Online Meeting (pp. 371-377). Medford, NJ: Learned Information.

Shaw, Debora. (1995). Bibliographic database searching by graduate students in language and literature: Search strategies, system interfaces, and relevance judgments. Library \& Information Science Research, 17, 327-345.

St. Clair, Glorianna \& Magrill, Rose Mary. (1990). Undergraduate term paper citation patterns by disciplines and level of course. Collection Management, 12 (3/4), 25-56.

Steffey, Ramona J. \& Meyer, Nikki. (1989). Evaluating user success and satisfaction with CD-ROM. Laserdisk Professional, 2, 35-45.

Sullivan, Patricia, \& Seiden, Peggy. (1985). Educating online catalog users: The protocol assessment of needs. Library Hi Tech, 3 (2), 11-19.

Tuckett, Harold W. (1988). Wilsondisc: A review. Reference Services Review, 16, 27-30.

Wallace, Patricia M. (1993). How do patrons search the online catalog when no one's looking? Transaction log analysis and implications for bibliographic instruction and system design. $R Q, 33,239-252$.

Whitaker, Cathy Seitz. (1990). Pile-up at the reference desk: Teaching users to use CD-ROMs. Laserdisk Professional, 3, 30-34.

Wiberley, Stephen E., Jr., Daugherty, Robert Allen. (1988). Users' persistence in scanning lists of references. College \& Research Libraries, 49, 149-156.

Wiberley, Stephen E., Jr., Daugherty, Robert Allen, \& Danowski, James. (1990). User persistence in scanning postings of a computer-driven information system: LCS. Library \& Information Science Research, 12, $341-353$.

Wurman, Richard Saul. (1989). Information anxiety, New York: Doubleday. 
Debora Shaw is Associate Professor and Associate Dean at the Indiana University School of Library and Information Science. She is the author of "Human-computer Interface for Information Retrieval" in the 1991 Annual Review of Information Science and Technology. In addition to human-computer interaction in information retrieval and information seeking, Dr. Shaw's research interests include interface design and diffusion of information technologies. 